\title{
Noninvasive ventilation in acute exacerbations of COPD
}

\author{
M.W. Elliott
}

\begin{abstract}
Noninvasive ventilation has been a major advance in the management of acute exacerbations of chronic obstructive pulmonary disease, reducing the need for endotracheal intubation, thereby reducing complications and hospital costs, as well as improving survival. It has been used in a variety of different clinical environments including the emergency room, on general wards, in intermediate respiratory care units and in the intensive care unit. It should now be regarded as part of standard therapy for patients who continue to have a respiratory acidosis after standard medical therapy.
\end{abstract}

KEYWORDS: Acute exacerbation, chronic obstructive pulmonary disease, noninvasive ventilation, obstructive lung disease, positive pressure ventilation, respiratory failure

$\mathbf{N}$ oninvasive ventilation (NIV) has been shown to be an effective treatment for ventilatory failure resulting from acute exacerbations of chronic obstructive pulmonary disease (COPD) [1-16]. It has been used in a variety of settings and in exacerbations of differing degrees of severity. These are summarised in table 1.

In the ICU studies [1-4] the most striking finding was a reduction in the need for endotracheal intubation (ETI) and mechanical ventilation (MV), which in the largest study translated into improved survival, reduced complication rates and length of both intensive care unit (ICU) and hospital stay [1]. Because paralysis and sedation are not needed with NIV, ventilation outside the ICU is an option; given the considerable pressure on ICU beds in most countries, the high costs and that for some patients admission to ICU is a distressing experience [17] this is an attractive option. NIV can be instituted at an earlier stage in the natural history of the condition before mechanical ventilation would normally be considered necessary. There have been a number of prospective randomised controlled studies of NIV outside the ICU either on general wards or in the Accident and Emergency Department [511]. NIV was instituted at a higher $\mathrm{pH}$ than that reported in the ICU studies and most failed to show any significant advantage to NIV when analysed on an intention-to-treat basis. These studies were all relatively small and may have lacked sufficient statistical power to show a difference in the need for intubation and mortality given that most patients with a mild exacerbation of COPD (defined by the degree of acidosis) would not be expected to need ETI and MV anyway [18]. In a large $(n=236)$ multicentre randomised controlled trial (RCT) of NIV in acute exacerbations of COPD on general respiratory wards in 13 centres [10] "treatment failure", a surrogate for the need for intubation, defined by a priori criteria, was reduced from $27 \%$ to $15 \%$ by NIV $(\mathrm{p}<0.05)$. In-hospital mortality was also reduced from $20 \%$ to $10 \% \quad(p<0.05)$. Subgroup analysis suggested that the outcome in patients with $\mathrm{pH}<7.30$ after initial treatment was inferior to that in the studies performed in the ICU. NIV was applied by the usual ward staff, most of whom had had little or no previous experience of NIV, using a bilevel device in spontaneous mode, according to a simple protocol. This study suggests that, with adequate staff training, NIV can be applied with benefit outside the ICU and that the early $(\mathrm{pH}<7.35$ on admission to the ward) introduction of NIV on a general ward results in a better outcome than providing no ventilatory support for acidotic patients outside the ICU. The results in the more severely affected patients ( $\mathrm{pH}<7.30$ after initial management) were not as good as those seen in the ICU studies, suggesting that this simple approach is not appropriate in these patients and that they are best managed in a higher dependency setting with a more sophisticated ventilator individually adjusted to their requirements.

A number of studies have suggested that NIV is less likely to be successful in more severely affected patients $[1,19,20]$ and all the studies reported to date have excluded patients who required immediate ETI and MV. The study of
CORRESPONDENCE

M.W. Elliott

St James's University Hospital

Consultant Respiratory Physician

Beckett Street

Leeds LS9 7TF

UK

Fax: 441132066042

E-mail: mwelliott@doctors.org.uk 


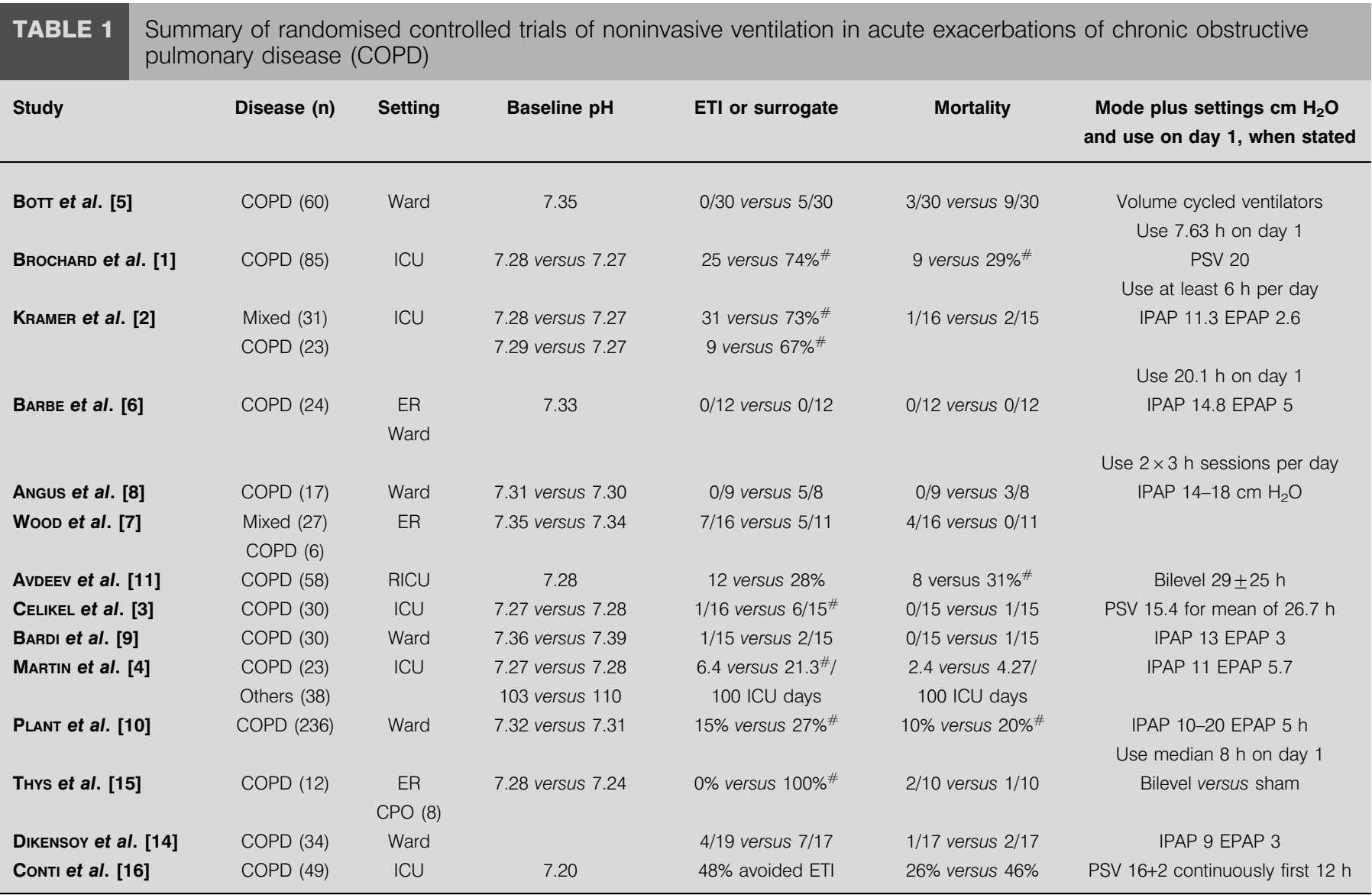

Data presented as $n$ or $n \pm S D$, unless otherwise stated. ETI: endotracheal intubation; ICU: intensive care unit; PSV: pressure support ventilation; IPAP: inspiratory positive airway pressure; EPAP: expiratory positive airway pressure; ER: emergency room; RICU: respiratory intermediate care unit; CPO: cardiographic pulmonary oedema. \#: $p<0.05$.

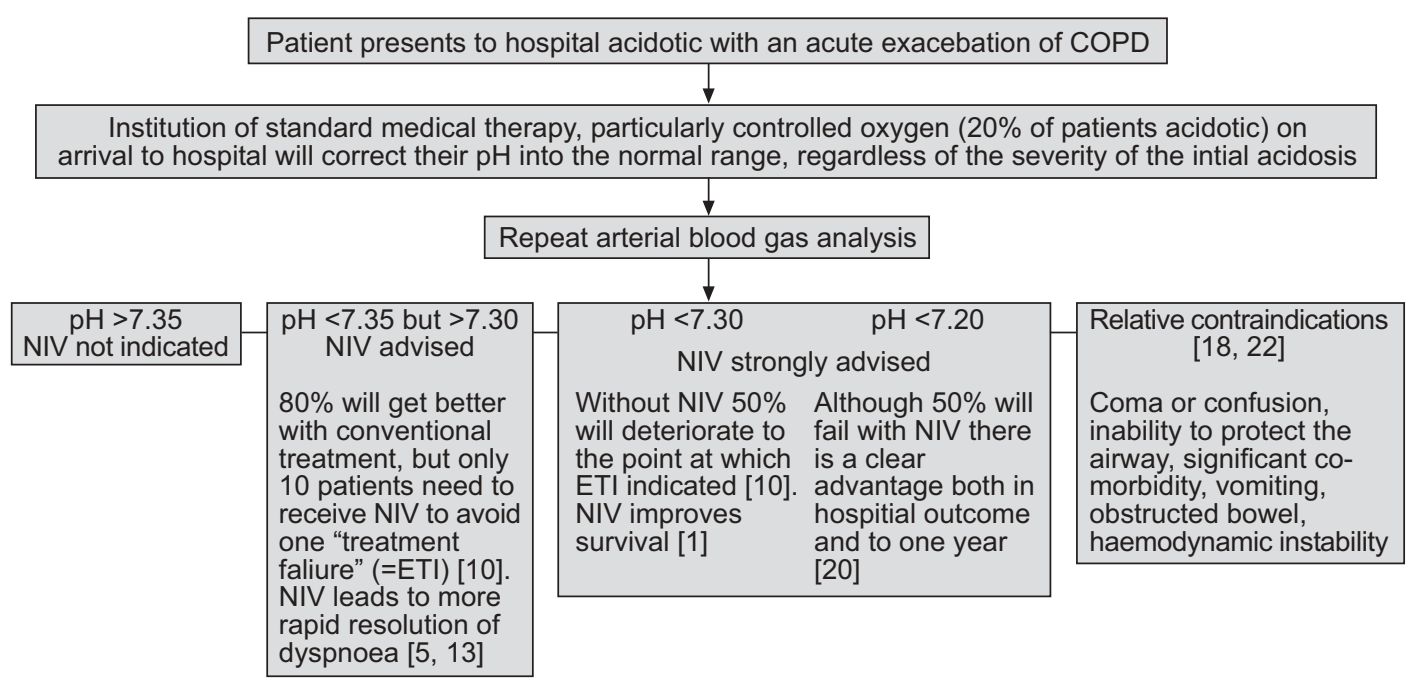

FIGURE 1. Suggested algorithm for the management of ventilatory failure in acute exacerbations of chronic obstructive pulmonary disease (COPD). NIV: noninvasive ventilation; ETI: endotracheal intubation. 
WoOD et al. [7] suggested that failure to move to ETI in a timely fashion may have explained a trend towards a worse survival in the NIV group. The concern has been voiced therefore, that, particularly in the more severely ill, NIV may be harmful by delaying the institution of ETI and MV. However CONTI et al. [16] recently reported a prospective RCT of NIV versus immediate ETI and MV in patients with an exacerbation of COPD. The intubation rate of $52 \%$ in the NIV group was higher than in other RCTs, which is not surprising given that these were a sicker group of patients, as evidenced by the mean $\mathrm{pH}$ of 7.2, compared with 7.27 in the study of BROCHARD et al. [1] and 7.32 in the study of PLANT et al. [10]. It reinforces the view that NIV is best instituted early [21]. However, in these sicker patients NIV was no worse than ETI and MV. In those who could be managed successfully with NIV there were important advantages both in the short term, but also in the year after hospital discharge. Some patients were still excluded and NIV remains a complimentary technique to invasive ventilation. An algorithm for the management of ventilatory failure in acute exacerbations of COPD is suggested in figure 1.

There are no absolute contraindications to NIV although a number have been suggested $[19,22]$. In part, these contraindications have been determined by the fact that they were exclusion criteria for the controlled trials. It is therefore more correct to state that NIV is not proven in these circumstances rather than that it is contraindicated.

When noninvasive ventilation can be successfully applied there are clear advantages, particularly a reduction in infectious complications [23-25] and length of intensive care unit and hospital stay [1], with an attendant reduction in costs $[26,27]$. There is no convincing evidence to date that a failed trial of noninvasive ventilation is harmful. However, there is always the danger that, as confidence grows, noninvasive ventilation may be continued for too long in an individual patient to the point of cardiorespiratory arrest. Further data are needed as to when noninvasive ventilation should be abandoned in favour of invasive ventilation. A trial of noninvasive ventilation is appropriate in the majority of patients acidotic because of an acute exacerbation of chronic obstructive pulmonary disease. Early intervention is more likely to be successful $[10,20,28]$, but even when patients present later in the natural history of their exacerbation there is still a significant role for noninvasive ventilation [16].

\section{REFERENCES}

1 Brochard L, Mancebo J, Wysocki M, et al. Noninvasive ventilation for acute exacerbations of chronic obstructive pulmonary disease. N Engl J Med 1995; 333: 817-822.

2 Kramer N, Meyer TJ, Meharg J, Cece RD, Hill NS. Randomized, prospective trial of noninvasive positive pressure ventilation in acute respiratory failure. Am J Respir Crit Care Med 1995; 151: 1799-1806.

3 Celikel T, Sungur M, Ceyhan B, Karakurt S. Comparison of noninvasive positive pressure ventilation with standard medical therapy in hypercapnic acute respiratory failure. Chest 1998; 114: 1636-1642.

4 Martin TJ, Hovis JD, Costantino JP, et al. A randomized, prospective evaluation of noninvasive ventilation for acute respiratory failure. Am I Respir Crit Care Med 2000; 161 807-813.

5 Bott J, Carroll MP, Conway JH, et al. Randomised controlled trial of nasal ventilation in acute ventilatory failure due to chronic obstructive airways disease. Lancet 1993; 341: 1555-1557.

6 Barbe F, Togores B, Rubi M, Pons S, Maimo A, Agusti AGN. Noninvasive ventilatory support does not facilitate recovery from acute respiratory failure in chronic obstructive pulmonary disease. Eur Respir J 1996; 9: 1240-1245.

7 Wood KA, Lewis L, Von Harz B, Kollef MH. The use of noninvasive positive pressure ventilation in the Emergency Department. Chest 1998; 113: 1339-1346.

8 Angus RM, Ahmed AA, Fenwick LJ, Peacock AJ. Comparison of the acute effects on gas exchange of nasal ventilation and doxapram in exacerbations of chronic obstructive pulmonary disease. Thorax 1996; 51: 1048-1050.

9 Bardi G, Pierotello R, Desideri M, Valdisseri L, Bottai M, Palla A. Nasal ventilation in COPD exacerbations: early and late results of a prospective, controlled study. Eur Respir J 2000; 15: 98-104.

10 Plant PK, Owen JL, Elliott MW. Early use of non-invasive ventilation for acute exacerbations of chronic obstructive pulmonary disease on general respiratory wards: a multicentre randomised controlled trial. Lancet 2000; 355: 1931-1935.

11 Avdeev SN, Tret'iakov AV, Grigor'iants RA, Kutsenko MA, Chuchalin AG. [Study of the use of noninvasive ventilation of the lungs in acute respiratory insufficiency due exacerbation of chronic obstructive pulmonary disease]. Anesteziol Reanimatol 1998; 3: 45-51.

12 Peter JV, Moran JL, Phillips-Hughes J, Warn D. Noninvasive ventilation in acute respiratory failure- a meta-analysis update. Crit Care Med 2002; 30: 555-562.

13 Lightowler JV, Wedzicha JA, Elliott MW, Ram FS. Noninvasive positive pressure ventilation to treat respiratory failure resulting from exacerbations of chronic obstructive pulmonary disease: Cochrane systematic review and metaanalysis. BMJ 2003; 326: 185-189.

14 Dikensoy O, Ikidag B, Filiz A, Bayram N. Comparison of non-invasive ventilation and standard medical therapy in acute hypercapnic respiratory failure: a randomised controlled study at a tertiary health centre in SE Turkey. International Journal of Clinical Practice 2002; 56: 85-88.

15 Thys F, Roeseler J, Reynaert M, Liistro G, Rodenstein D. Noninvasive ventilation for acute respiratory failure: a prospective randomised placebo-controlled trial. Eur Respir J 2002; 20: 545-555.

16 Conti G, Antonelli M, Navalesi P, et al. Noninvasive vs. conventional mechanical ventilation in patients with chronic obstructive pulmonary disease after failure of medical treatment in the ward: a randomized trial. Intensive Care Med 2002; 28: 1701-1707.

17 Easton C, MacKenzie F. Sensory-perceptual alterations: delirium in the intensive care unit. Heart Lung 1988; 17: 229-237.

18 Jeffrey AA, Warren PM, Flenley DC. Acute hypercapnic respiratory failure in patients with chronic obstructive lung disease: risk factors and use of guidelines for management. Thorax 1992; 47: 34-40. 
19 Ambrosino N, Foglio K, Rubini F, Clini E, Nava S, Vitacca $M$. Non-invasive mechanical ventilation in acute respiratory failure due to chronic obstructive airways disease: correlates for success. Thorax 1995; 50: 755-757.

20 Plant PK, Owen JL, Elliott MW. Non-invasive ventilation in acute exacerbations of chronic obstructive pulmonary disease: long term survival and predictors of in-hospital outcome. Thorax 2001; 56: 708-712.

21 Evans TW. International Consensus Conferences in Intensive Care Medicine: non-invasive positive pressure ventilation in acute respiratory failure. Organised jointly by the American Thoracic Society, the European Respiratory Society, the European Society of Intensive Care Medicine, and the Societe de Reanimation de Langue Francaise, and approved by the ATS Board of Directors, December 2000. Intensive Care Med 2001; 27: 166-178.

22 Soo Hoo GW, Santiago S, Williams AJ. Nasal mechanical ventilation for hypercapnic respiratory failure in chronic obstructive pulmonary disease: determinants of success and failure. Crit Care Med 1994; 22: 1253-1261.

23 Girou E, Schortgen F, Delclaux C, et al. Association of noninvasive ventilation with nosocomial infections and survival in critically ill patients. JAMA 2000; 284: 2361-2367.
24 Nourdine $K$, Combes $\mathrm{P}$, Carton M-J, Beuret $\mathrm{P}$, Cannamela A, Ducreux J-C. Does noninvasive ventilation reduce the ICU nosocomial infection risk? A prospective clinical survey. Intens Care Med 1999; 25: 567-573.

25 Carlucci A, Richard JC, Wysocki M, Lepage E, Brochard L. Noninvasive versus conventional mechanical ventilation. An epidemiologic survey. Am J Respir Crit Care Med 2001; 163: 874-880.

26 Keenan SP, Gregor J, Sibbald WJ, Cook DJ, Gafni A. Noninvasive positive pressure ventilation in the setting of severe, acute exacerbations of chronic obstructive pulmonary disease: More effective and less expensive. Crit Care Med 2000; 28: 2094-2102.

27 Plant PK, Owen JL, Parrott S, Elliott MW. Cost effectiveness of ward based non-invasive ventilation for acute exacerbations of chronic obstructive pulmonary disease: economic analysis of randomised controlled trial. BMJ 2003; 326: 956-961.

28 Plant PK, Owen J, Elliott MW. One year period prevalance study of respiratory acidosis in acute exacerbation of COPD; implications for the provision of non-invasive ventilation and oxygen administration. Thorax 2000; 55: 550-554. 